\title{
Comparative Genome Analysis of Vibrio vulnificus, a Marine Pathogen
}

\author{
Chung-Yung Chen, ${ }^{1,6}$ Keh-Ming Wu, ${ }^{1,6}$ Yo-Cheng Chang, ${ }^{2}$ Chuan-Hsiung Chang, ${ }^{3}$ \\ Hui-Chi Tsai, ${ }^{1}$ Tsai-Lien Liao, ${ }^{1}$ Yen-Ming Liu, ${ }^{1}$ Hsiang-Ju Chen, ${ }^{1}$ Arthur Bo-Ting Shen, ${ }^{4}$ \\ Jian-Chiuan Li, ${ }^{1}$ Teh-Li Su, ${ }^{1}$ Chung-Ping Shao, ${ }^{5}$ Chung-Te Lee, ${ }^{5}$ Lien-I Hor, ${ }^{5}$ and \\ Shih-Feng Tsai ${ }^{1,3,4,7}$ \\ ${ }^{1}$ Division of Molecular and Genomic Medicine, National Health Research Institutes, Taipei 115, Taiwan; ${ }^{2}$ Biomedical Engineering \\ Center, Industrial Technology Research Institute, Hsinchu 310, Taiwan; ${ }^{3}$ Institute of Genetics and ${ }^{4}$ Genome Research Center, \\ National Yang-Ming University, Taipei 112, Taiwan; ${ }^{5}$ Department of Microbiology and Immunology, National Cheng Kung \\ University, Tainan 701, Taiwan
}

\begin{abstract}
The halophile Vibrio vulnificus is an etiologic agent of human mortality from seafood-borne infections. We applied whole-genome sequencing and comparative analysis to investigate the evolution of this pathogen. The genome of biotype 1 strain, V. vulnificus YjO16, was sequenced and includes two chromosomes of estimated $3377 \mathrm{kbp}$ and 1857 $\mathrm{kbp}$ in size, and a plasmid of 48,508 bp. A super-integron (SI) was identified, and the SI region spans $139 \mathrm{kbp}$ and contains 188 gene cassettes. In contrast to non-SI sequences, the captured gene cassettes are unique for any given Vibrio species and are highly variable among $V$. vulnificus strains. Multiple rearrangements were found when comparing the 5.3-Mbp V. vulnificus Yj016 genome and the 4.0-Mbp V. cholerae El Tor N16961 genome. The organization of gene clusters of capsular polysaccharide, iron metabolism, and RTX toxin showed distinct genetic features of $V$. vulnificus and $V$. cholerae. The content of the $V$. vulnificus genome contained gene duplications and evidence of horizontal transfer, allowing for genetic diversity and function in the marine environment. The genomic information obtained in this study can be applied to monitoring vibrio infections and identifying virulence genes in $V$. vulnificus.
\end{abstract}

[Supplemental material is available online at www.genome.org and at http://genome.nhri.org.tw/vv/. The nucleotide sequence data from this study have been submitted to DDB]/EMBL/GenBank under accession nos. BA000037,

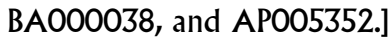

\begin{abstract}
Vibrio vulnificus is an etiologic agent for severe human infection acquired through wounds or contaminated seafood. This organism is divided into three biotypes according to their different biochemical and biological properties (Linkous and Oliver 1999). Among them the biotype 1 strains are most frequently isolated from the clinical specimens. Opportunistic infection in susceptible individuals typically causes mortality within 24 to $48 \mathrm{~h}$ of the exposure. The bacterium is halophilic, and it is abundantly present in estuarine ecosystems throughout the world. Isolated incidents of $V$. vulnificus infection have been reported in the U.S.A., Europe, Korea, Taiwan (Park et al. 1991; Chuang et al. 1992; Dalsgaard et al. 1996; Hlady and Klontz 1996), and many other countries. According to CDC statistics, V. vulnificus is a major bacterial cause of mortality associated with food-borne diseases, and it results in the highest death rate of any causative agent (Todd 1989).

$V$. vulnificus belongs to the $\gamma$-group of Proteobacteria, and it shares morphological and biochemical characteristics with other human vibrio pathogens, including Vibrio cholerae and Vibrio parahaemolyticus. Bacteria of the Vibrionaceae family, which show a comma-shape microscopic appearance and a polar flagellum appendage, are mostly aquatic inhabitants that require $\mathrm{NaCl}$ for optimal growth. On the basis of clinical and epidemiology studies, diseases associated with $V$. vulnificus infection have been
\end{abstract}

6These authors contributed equally to this work.

7 Corresponding author.

E-MAIL petsai@nhri.org.tw; FAX 886-28200552.

Article and publication are at http://www.genome.org/cgi/doi/10.1101/ gr.1295503. found to present in two patterns (Blake et al. 1979). In one, primary septicemia occurred in individuals with chronic liver disease, shortly after eating raw oysters, with a mortality rate of over $50 \%$. In the other pattern, wound infections incurred via exposure to seawater or handling seafood products, with a death rate of approximately 25\% (Hlady and Klontz 1996).

Regardless of entry route, a hallmark of $V$. vulnificus infection is fulminant reaction caused by the invading bacteria in connective tissues, displayed as blisters and hemorrhagic necrosis, and sometimes requiring radical treatment (Chuang et al. 1992). Biochemical and genetic studies suggest that extracellular proteins released by the invading bacteria mediate the pathogenesis process of penetrating cellular barriers, vascular dissemination, and local destruction of affected tissues. Even in nonfatal cases, V. vulnificus infection evokes intensive tissue damage and, occasionally, results in amputation and disability.

To investigate virulence factors and the invasive nature of $V$. vulnificus infection, we chose a comparative genomics approach to uncover critical events leading to the functional uniqueness of Vibrio species, and consequently, distinct clinical pictures of humans exposed to the pathogenic bacteria. We selected strain YJ016 (Shao and Hor 2000), a biotype 1 hospital isolate from Taiwan, as a target for sequencing. Here we report the complete nucleotide sequence of the pathogenic $V$. vulnificus YJ016 genome and the comparative analysis of $V$. vulnificus with recently obtained genome sequences of $V$. cholerae (Heidelberg et al. 2000) and V. parahaemolyticus (Makino et al. 2003). We discovered a significant difference in chromosomal organization of the vibrio pathogens, and we identified several mechanisms underlying the 
Table 1. Global Features of the Vibrio vulnificus Yj016 Genome

\begin{tabular}{lccc}
\hline & Chromosome & Chromosome & \\
& $\mathbf{1}$ & $\mathbf{2}$ & pYJ016 \\
\hline Size (bp) & $3,354,505^{\mathrm{a}}$ & $1,857,073$ & 48,508 \\
Sequencing reads & 52,017 & 33,810 & 2,690 \\
G C percentage & 46.4 & 47.2 & 44.9 \\
Total number of ORFs & 3,262 & 1,697 & 69 \\
Average ORF size (bp) & 912 & 989 & 659 \\
Percentage coding & $88.7 \%$ & $90.3 \%$ & $89.8 \%$ \\
Number of rRNA & 8 & 1 & 0 \\
operons & 100 & 12 & 0 \\
Number of tRNAs & 100 & 12 & 0 \\
\hline
\end{tabular}

aExcluding a 23-kb gap of tandem-repeat sequence.

dynamic evolution of the bacteria. In addition, sequences encoding potential virulence determinants were considered for the pathophysiology of human infection with reference to the newly available information from the $V$. vulnificus genome.

\section{RESULTS}

\section{Complete Nucleotide Sequence of $V$. vulnificus YjO16}

From 88,517 reads of raw data, we assembled the genomic sequence of $V$. vulnificus YJ016 into two circular chromosomes of $3,354,505$ bp and 1,857,073 bp, respectively (Table 1, Fig. 1). A gap of approximately $23 \mathrm{~kb}$ in the large chromosome remains recalcitrant to sequencing, as it contains an estimated 77 units of 297-bp in-tandem repeat (data not shown). Therefore, the size of the large chromosome is estimated to be $3377 \mathrm{kbp}$ in size. Additionally, a plasmid of 48,508 bp was identified. Overall, the large chromosome has a GC content of $46.4 \%$, and the small chromosome $47.2 \%$. Using the Glimmer (Salzberg et al. 1998) and the GeneMark (Borodovsky and McIninch 1993) software programs, 4959 and 69 coding sequences (CDS) were predicted from the chromosomal and plasmid sequences, respectively.

The genomic content of $V$. vulnificus was examined, relative to $V$. cholerae (Heidelberg et al. 2000), to reveal the genetic basis for functional distinction of the bacteria. The V. vulnificus YJ016 genome contains 1143 more genes than in V. cholerae El Tor N16961. The chromosomal genes can be classified, according to phylogenetic analysis, into four major groups and 18 subgroups (see Supplemental information) on the basis of the COG (Cluster of Orthologous Groups; http://www.ncbi.nlm.nih.gov/COG/; Tatusov et al. 1997). Approximately 34\% (1688/4959) of the chromosomal genes are hypothetical in nature, and they account for the majority of genes that are unique to the $V$. vulnificus genome. For the remaining functionally known genes, we examined the distribution in different COG groups. Overall, the distribution of COG in $V$. vulnificus is similar to that in other $\gamma$-proteobacteria (V. cholerae, V. parahaemolyticus, Escherichia coli, Pseudomonas aeruginosa) and most $(1183 / 4959,24 \%)$ of the predicted chromosomal genes are related to a metabolic function. Of these, carbohydrate transport and metabolism and amino acid transport and metabolism accounted for 21\% (247/1183) and $27 \%$ (320/1183), respectively, of this major COG group. On the other hand, transcription and signal transduction mechanisms are well represented in the major groups of information storage and processing, and cellular processes. Using $V$. cholerae as a reference, $V$. vulnificus was found to be slightly larger in three functional subgroups (transcription, carbohydrate transport and metabolism, and secondary metabolism biosynthesis). Thus, V. vulnificus shares much of the genome content with $V$. cholerae, although a significant number of new features seem to have evolved.

\section{A Conjugation Plasmid}

A circular plasmid molecule (designated pYJ016, hereafter) of 48,508 bp was identified from the assembled sequences. An open reading frame $(\mathrm{ORF})$ of putative replication initiator protein (RepA) and a nearby structure of putative origin of replication (ori), containing DnaA boxes, RepA-binding sites, palindrome sequences, and two stretches of iterons, were found on this circular molecule.

A total of 69 ORFs were predicted from the plasmid sequence. Notably, several genes related to plasmid conjugation (traB, -C, -D, -E, -F, -G, -H, -I, -K, -L, -N, -U, -W, -Y, trbB, -C) are present in the pYJ016 sequence. The orientation and arrangement of these tra genes are strikingly similar to those of the $\mathrm{F}$ plasmid (Kennedy et al. 1977), except that the pYJ016 plasmid lacks traM, -J, -A, - $\mathrm{P},-\mathrm{V},-\mathrm{R},-\mathrm{E},-\mathrm{Q},-\mathrm{S}$, and $-\mathrm{T}$ that are involved in pilus formation (Moore et al. 1981; Maneewannakul et al. 1993) and associated functions. Despite this apparent deficiency, the pYJ016 plasmid was transferred between bacteria by conjugation in the laboratory system (L.-I Hor, unpubl.).

\section{V. vulnificus Super-Integron}

A region which shows multiple repeats and unusual GC content and GC skew in the large chromosome was identified (Fig. 1, 7 o'clock position). Alignment of the repetitive sequences revealed a consensus sequence that is suggestive of super-integron (SI) cassette (Mazel et al. 1998). The SI of vibrio bacteria typically includes an integrase (intI), a proximal primary recombination site (attI), multiple target-specific recombination sites (attC), and associated gene cassettes (Rowe-Magnus et al. 1999). The attC sequences in the $V$. vulnificus genome can be recognized by a conserved 6-bp boundary sequence of TAAC-AA at the 5'-end and a partially complementary 6-bp boundary sequence of GCGTTA at the 3'-end. This signature of SI is conserved between $V$. cholerae (Heidelberg et al. 2000) and V. parahaemolyticus (Makino et al. 2003), and it is consistent with the consensus of the two core sites (inverse core: RYYYAAC; core: GTTRRRY) for integrons (Stokes and Hall 1989; Collis et al. 1998). A total of 188 attC sites were found in the $V$. vulnificus SI, and the entire SI region spans $138 \mathrm{kbp}$ in the large chromosome (Fig. 2). In contrast, 175 attC sites were found in the $V$. cholerae El Tor N16961 genome, and the SI region spans 126-kbp sequence on the small chromosome (Heidelberg et al. 2000).

\footnotetext{
Figure 1 Genomic organization of the $V$. vulnificus chromosomes. The two chromosomes are depicted by circular representation. From the outside inward: The first and second circles show predicted protein-coding regions on the plus and minus strands, by role, according to the color code of the COG functional categories. The third circle shows percentage $G+C$ in relation to mean $G+C$ for the chromosome. The fourth circle shows $G C$ skew. The fifth circle shows super-integron (pink), type IV pilus genes (blue), capsular polysaccharide biosynthesis genes (green), iron acquisition genes (brown), extracellular enzyme and toxin genes (sky), and RTX genes (red). The sixth and seventh circles are tRNAs and rRNAs, respectively. Bottom: color code for the COG functional categories. J, translation, ribosomal structure, and biogenesis; K, transcription; L, DNA replication, recombination and repair; D, cell division and chromosome partitioning; $\mathrm{O}$, posttranslational modification, protein turnover, chaperones; $\mathrm{M}$, cell envelope biogenesis, outer membrane; N, cell motility and secretion; $\mathrm{P}$, inorganic ion transport and metabolism; $\mathrm{T}$, signal transduction mechanisms; $\mathrm{C}$, energy production and conversion; $G$, carbohydrate transport and metabolism; $E$, amino acid transport and metabolism; $F$, nucleotide transport and metabolism; $H$, coenzyme metabolism; I, lipid metabolism; Q, secondary metabolites biosynthesis, transport, and catabolism; R, general function prediction only; S, function unknown.
} 

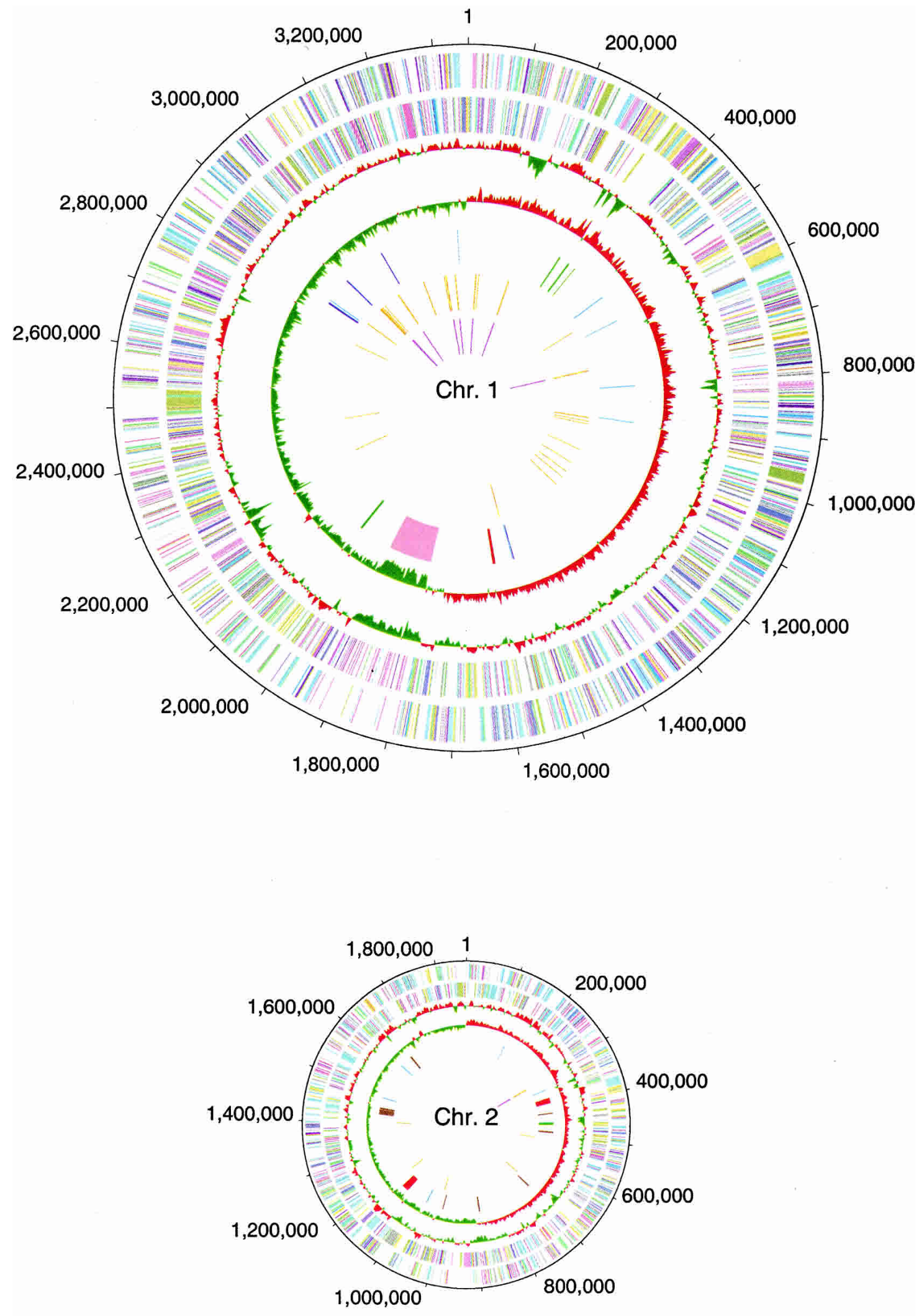

\section{\begin{tabular}{l|lllllllllll|l|llllllll} 
J & K & L & $D$ & O & $M$ & N & $P$ & T & C & G & E & F & H & I & Q & $R$ & $S$
\end{tabular}}


Chen et al.

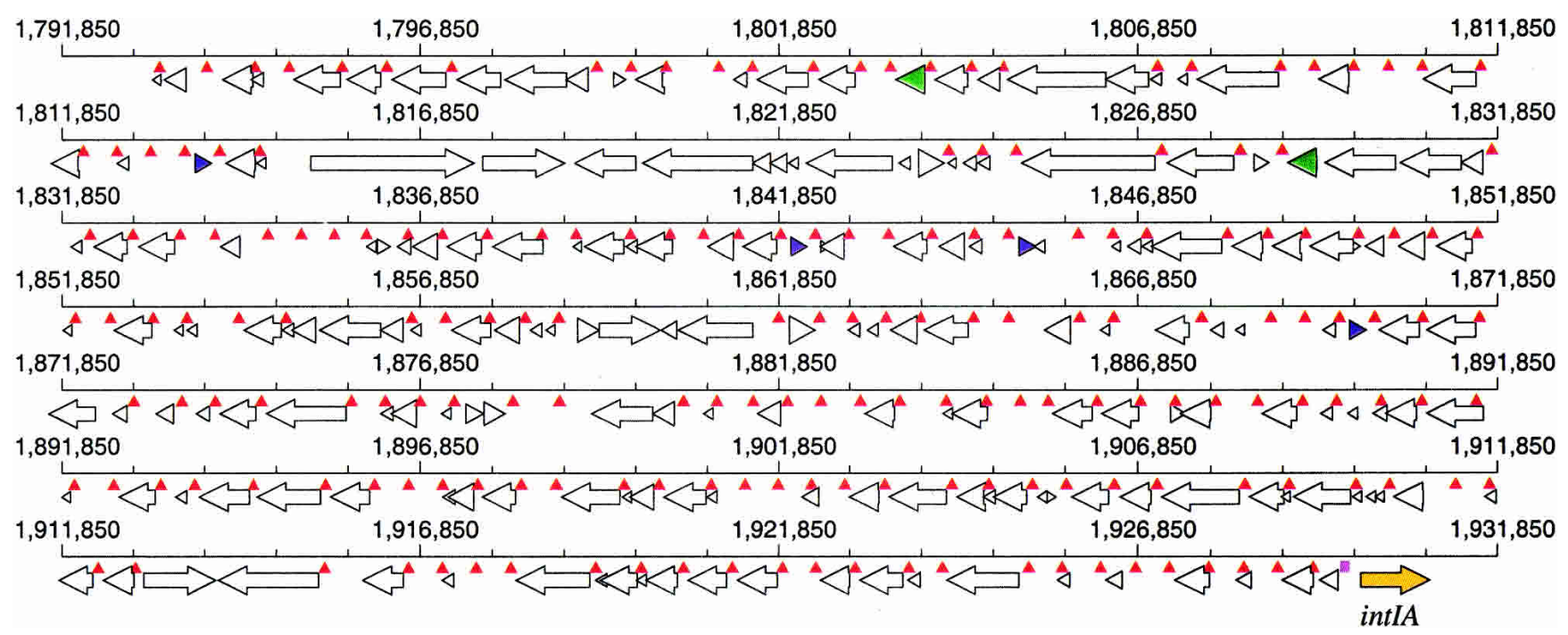

Figure 2 Organization of the $V$. vulnificus YJ016 super-integron. The integrase gene, intlA, is shown as a yellow arrow and the neighboring primary integration site (attl) as a purple square next to the intIA. The 188 attC sites are indicated by red triangles. The 202 ORFs are indicated by arrows, with two NTP pyrophosphohydrolase (mutT) genes and four PAS genes in green and blue, respectively.

From within the SI region of V. vulnificus, 202 ORFs were identified. More than three-quarters (160, 79\%) are hypothetical genes in nature. Only $42(21 \%)$ ORFs can be assigned a tentative function by the protein motif of the ORF, and the coding sequences of these functional ORFs are related to homologous sequences from a wide range of organisms. This finding is in accordance with the postulate that the SI of vibrio bacteria serves as a capture system that can acquire DNA from the surrounding environment (Rowe-Magnus and Mazel 1999; Rowe-Magnus et al. 1999).

Genetic variability of the $V$. vulnificus SI sequences appears to be enhanced by duplication and transposition events. Five copies of identical sequence bearing a transposase motif were found within and outside the SI region, with one in the SI (VV1842), three on the large chromosome (VV1738, VV2191, VV3176), and one on the small chromosome (VVA1413). We grouped the coding sequences in the SI region by conducting pair-wise comparison using the BLASTX program. Of the 202 ORFs in the SI region, 83 sequences can be classified into 29 paralogous groups (the criteria and results of assigning paralogous groups are in the Supplemental information). The number of duplicated sequences ranges from two to seven for each group. In contrast, using the same criteria, only 33 paralogous groups (a total of 80 genes) were identified from outside the SI region in the $V$. vulnificus genome. Alignment of paralogous SI genes revealed that mutation occurred frequently in duplicated sequences (Fig. 3). For example, two copies of mutT genes (Fowler and Schaaper 1997) were identified from the SI region, and there are 12 nucleotide (nt) substitutions in the 408-bp gene, accounting for two amino acid (aa) changes in the 135-aa ORF. The mut $T$ gene sequences (VV1754, VV1786) of V. vulnificus YJ016 showed significant homology to that of the Streptococcus pneumoniae R6, Streptococcus pneumonia TIGR4, and P. aeruginosa PA01 (Fig. 3A). On the other hand, two types of sequences were found for the four PAS factor genes (Tokugawa et al. 1994; VV1767, VV1806, VV1812, VV1854), and they differ in $8 \mathrm{nt}$ in a 231-bp segment, resulting in two amino acid changes in the 76-aa ORF (Fig. 3B).

\section{Pathogenicity}

The highly invasive behavior of $V$. vulnificus that causes fulminant septicemia in humans has been postulated to be associated with multiple virulence factors: the capsular polysaccharide (CPS) that confers resistance to phagocytosis and serum killing (Wright et al. 1990), and a few extracellular proteins (Linkous and Oliver 1999; Strom and Paranjpye 2000). In addition, it is well documented that iron availability in the host can effect $V$. vulnificus growth in a mouse model or in an in vitro culture system (Wright et al. 1981). On the basis of the whole-genome sequence, we identified the $V$. vulnificus genes that might encode the various virulence factors. A list of putative pathogenicity genes and annotated information is provided as Supplemental information (http://genome.nhri.org.tw/vv/).

We examined five groups of genes (type IV pilus, capsular polysaccharide biosynthesis, iron acquisition, extracellular enzyme and toxin, and repeat in toxin RTX [repeat in toxin] toxin) regarding their distribution and organization in the two chromosomes (Figs. 1,4). Overall, a large fraction of these genes are on the small chromosome, and typically, genes of the same group are mapped to the same chromosome. For example, genes related to type IV pilus biosynthesis and genes for iron acquisition are on the large and the small chromosome, respectively. Except for one, most RTX genes are on the small chromosome.

Eight genes encoding the components for synthesis of type IV pilus, which may mediate adherence to the host cells and motility, were identified on the large chromosome. However, no ORF with a sequence homologous to any gene known to be involved in bacterial invasion into the host cells (e.g., intimin in enteropathogenic E. coli and internalins in Listeria monocytogenes) was found. This is consistent with our previous finding that $V$. vulnificus YJ016 does not invade cultured epithelial cells (L.-I Hor, unpubl.), suggesting that this organism is unable to translocate across the gastrointestinal wall to the bloodstream by a transcytosis mechanism.

Sixteen genes possibly encoding the enzymes involved in biosynthesis and transport of CPS were identified. Three of them (VV0337, VV0339, VV0340) showed sequence homology to wza, $w z b$, and $w z c$ genes of the "translocation-surface assembly" cluster in E. coli (Rahn et al. 1999), and they displayed similar organization to the previously reported group 1-like CPS operon of $V$. vulnificus MO6-24/O (Fig. 4A; Wright et al. 2001). In V. cholerae El Tor N16961 this operon is lacking, but one gene set (VC0934, VC0936, VC0937) showed low sequence homology to the E. coli 
A

VV1754

VV1786

NP_761339

NP_251870

NP_346216

NP_359201

VV1754

VV1786

NP_761339

NP_251870

NP_346216

NP_359201

VV1754

VV1786

NP 761339

NP_251870

NP_346216

NP_359201

B

VV1767

VV1806

VV1812

VV1854

AAC60476
---VQHFKGCKLVVHCNEQILTYKRDNISSISYPNCWDLPGGGREGNETPEDCALRELK

-.--VQHFKGCKLVVHCNEQIITYKRDNISSISYPNCWDLPGGGREGNETPEDCALREFK

----MQHFNGCKLVVHCNEQILTYKRDNISSISYPNCWDLPGGGREGNETPEDCALRELK

-MHDVPPFSGAKLALFYGDHLVVYKRDEKPGIPFPGYWDF PGGGREGLETPAECALRELE

MELEISDFTGCKIALFCGDKLLTILRDDKASI PWANMWELPGGGREGDESPFECARREVY

MELEI SGFPGCKIALFCGDKLLTILRDDKASI PWANMWELPGGGREGDESPFECVAREVY

EEFGIELCPSRIHYKQKVESHTGFG-CAYFLAVTITESELREIQFGDEGQYWKLMDIETY

EEFGIELCPSRIHYKQKVESHTGFG-CAYFLAVTITESELREIQFGDEGQYWKLMDIETY

EEFGIELCPSRIHYKOKVESHTGFG-CAYFLAVTITESELREIQFGDEGQYWKLMDIETY

EEFSIRLEEPRIEWQRQYPSTSGSAPFAYFLVARLEDREFEAIRFGDEGQYWRLMEVDAY

EELGIHLDEDCLLWSKIYPSVIFKGKKSVFMVGQLRQEQFDNIIFGDEGQGYQLMNVEEF

EELGIHLTEDCLLWSKVYPSMLFADKQSVFLVGQLTQNQFDSIVFGDEGQGYQLMNVEEF

LALPDAVPSNQQRIRGYLNL------

135

LALPDAVPSNQQRIRGYLNL--.---

135

LALSDAVPSNQQRIRGYLNL_-_-_--

135

LAHAMAVPYLQSRLGDYLRERRRIGE

145

LSSSQVVPQLQERLKDYLKVSD----

142

LSSSQVVPQLQERLKDYLKVSD----

142
56

56

56

59

60

60

115

115

115

119

120

120

$\begin{array}{lll}\text { VV1767 } & \text { MKALIYETLVNLANQDPEQHATIRQ } \\ \text { VV1806 } & \text { MKALIYETLVNLANQDPEQHATIRQ } \\ \text { VV1812 } & \text { MKALIYETLVNLANQDPEQHATIRQ } \\ \text { VV1854 } & \text { MKALIYETLVNLTNQDPEQHATIRQ } \\ \text { AAC60476 } & \text { MKTLIYETLISLANQEPEQHARIRQ } \\ & & \\ \text { VV1767 } & \text { SNAVDSVVQLLEIPEH } & 76 \\ \text { VV1806 } & \text { SNAVDSVVQLLEIPEH } & 76 \\ \text { VV1812 } & \text { SNAVDSVVQLLEIPEH } & 76 \\ \text { VV1854 } & \text { SNAVDRVVQLLEIPEH } & 76 \\ \text { AAC60476 } & \text { NNAVDCAVKLLETPER } & 76\end{array}$

Figure 3 Amino acid sequence variation in duplicated SI genes and their relationship to other bacterial sequences. Multiple sequences were aligned using CLUSTALW. (A) NTP pyrophosphohydrolase (MutT) gene of V. vulnificus, strain YJ016 (VV1754, VV1786), strain CMCP6 (NP_761339.1); $P$. aeruginosa PA01 (NP_251870); S. pneumoniae, TIGR4 strain (NP_346216), R6 strain (NP_359201). (B) PAS gene of V. vulnificus YJ016 (VV1767, VV1806, VV1812, VV1854) and V. alginolyticus (AAC60476).

$w c a J$, wza, and wzc genes. In V. vulnificus YJ016, one set each of linked wcaJ-wza-wzc genes was identified in the large chromosome (VV2040-VV2043) and the small chromosome (VVA0392VVA0395). The function of the duplicated gene sets is not known.

Heterogeneous capsular types have been found among various clinical and environmental isolates (Hayat et al. 1993), suggesting that different strains may use different, at least partially, metabolic pathways for biosynthesis of CPS. The absence of an epimerase gene required for capsule synthesis (Zuppardo and Siebeling 1998) of strain 1003(O) from the genome sequence of YJ016 is consistent with this notion. Smith and Siebeling (2003) recently applied a transposon mutagenesis approach and identified, from strain 1003(O), four genetic regions that are essential to CPS expression and virulence. From these noncapsulated strains, the insertion of the transposon was mapped to $w c v A$, $w c v F, w c v I$, and an ORF in the SI region. We searched these sequences against available $V$. vulnificus genome sequences and found that only the locus $w c v I / w c v H$ was present in both YJ016
(VVA0389, VVA0390) and CMCP6. The other loci were either incomplete in YJ016 (VV301-VV303) or absent in YJ016 or CMCP6. Altogether, the data provide a genetic basis for variable CPS features and antigenic diversity among $V$. vulnificus strains.

Genes encoding different components of the iron utilization systems have been identified in E. coli and $V$. cholerae, and we discovered the corresponding genes from several clusters in the YJ016 genome (Fig. 4B,C). Notably, all iron metabolism gene clusters identified from $V$. vulnificus YJ016 are on the small chromosome, whereas in V. cholerae El Tor N16961 the corresponding gene clusters are distributed over the large and small chromosomes. Chromosomal rearrangements involving these loci are evident by comparing the organization of the homologous gene clusters in the two vibrio pathogens (Fig. 4B,C).

A number of extracellular enzymes and toxins, including metalloprotease, phospholipase, and cytolysin, have been implicated in causing tissue destruction and subsequent bacterial invasion into the blood stream (Linkous and Oliver 1999; Strom 
A

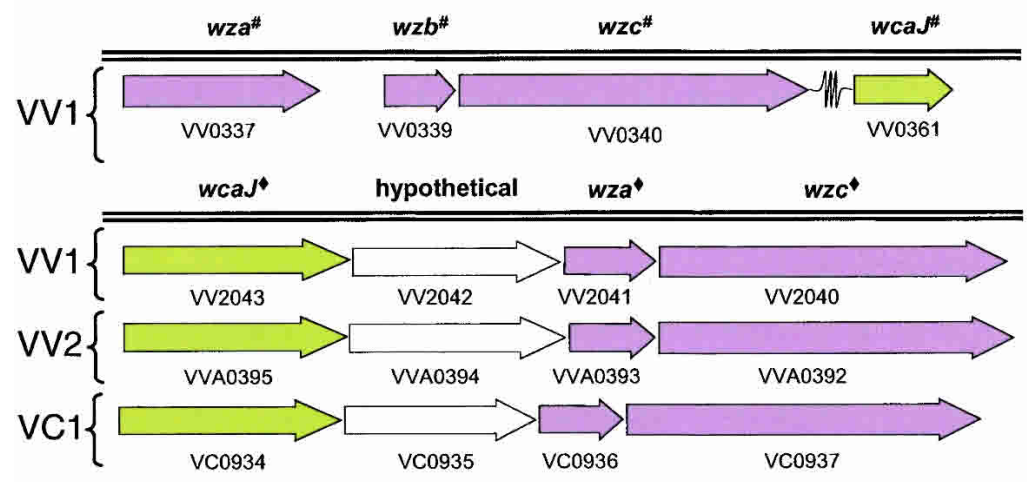

B

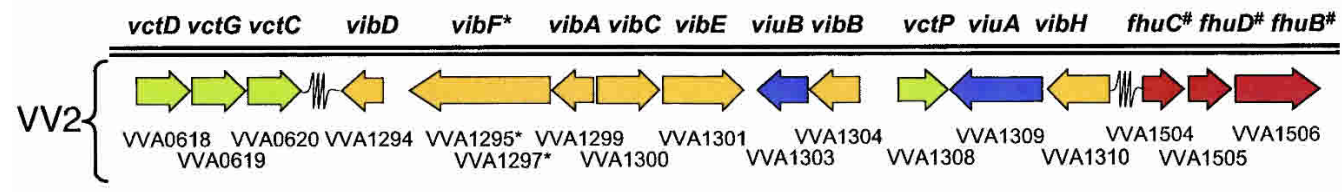

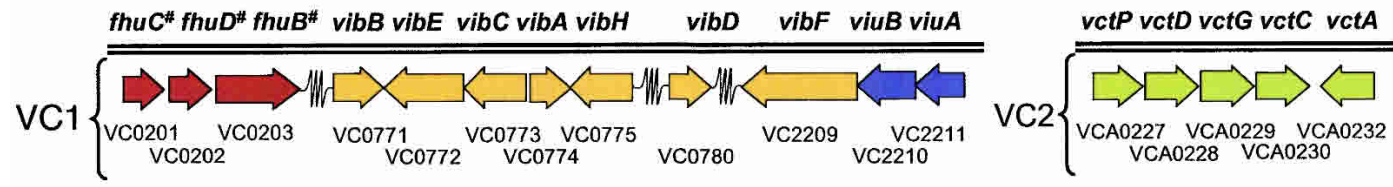

C
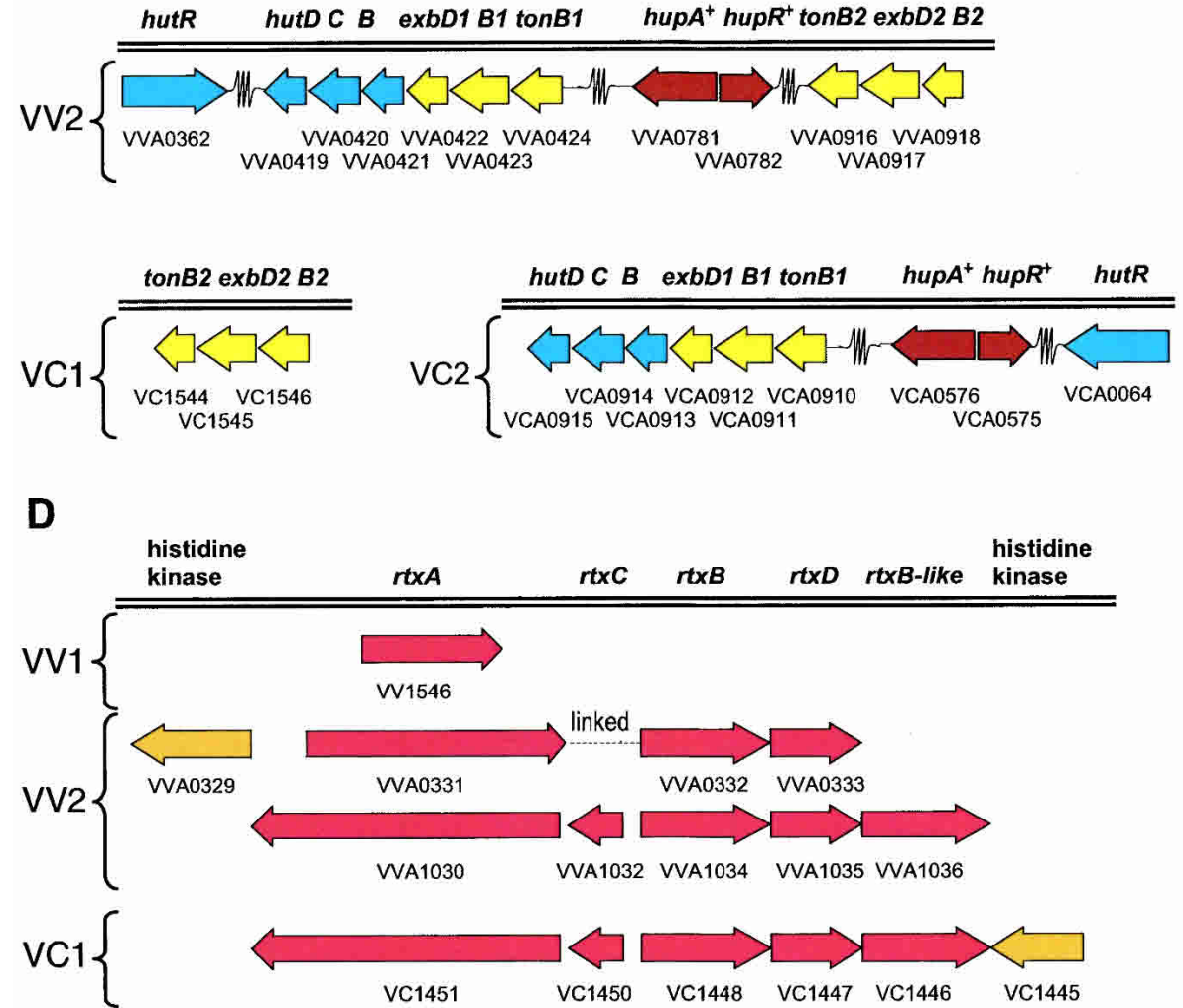

Figure 4 Gene clusters related to $V$. vulnificus pathogenicity. $(A)$ Capsular polysaccharide, $(B)$ siderophore biosynthesis and transport, $(C)$ heme receptor and transport, $(D)$ RTX. The diagrams (not to scale) depict the gene clusters and paralogous members in $V$. vulnificus Yj016 and the corresponding segments and genes in V. cholerae El Tor N16961. VV1, the large chromosome of V. vulnificus; VV2, the small chromosome of V. vulnificus; $\mathrm{VC} 1$, the large chromosome of $V$. cholerae; VC2, the small chromosome of $V$. cholerae. Unless specifically given, gene names for $V$. cholerae are used to indicate the corresponding loci in the $V$. vulnificus genome. (\#) E. coli gene name, $(\diamond)$ low homology to $E$. coli gene, $(\dagger) V$. vulnificus gene name, $\left({ }^{*}\right)$ two ORFs.

\section{Genome Research}

www.genome.org 
and Paranjpye 2000). A cytolysin gene, vvhA (VVA0965) was uniquely present on the small chromosome, and the gene has little homology with other known genes except for two short regions of 78 and $57 \mathrm{nt}$. A metalloprotease gene, $v v p$ (VVA1465), and a phospholipase gene, $v p l$ (VVA0303), both of which are highly homologous to those in $V$. cholerae, are located on the small chromosome.

Although purified metalloprotease and cytolysin produced pathologic effects in a variety of animal models (Linkous and Oliver 1999; Strom and Paranjpye 2000), a mutant deficient in both factors is only slightly reduced in its virulence in mice (Fan et al. 2001). In addition, this mutant, as well as another mutant with a third mutation in a phospholipase gene, was as cytotoxic to the epithelial cells as the parental strain (L.-I Hor, unpubl.), suggesting the presence of still unidentified cytotoxin(s). Indeed, as listed in the Supplemental information, 13 homologs of known cytotoxins (VVA0964, VVA0965), hemolysins (VV0508, VV0601, VV0795, VV0914, VV1495, VV2791, VV3230, VVA0118, VVA0303, VVA1339), and RTX toxin (VVA1030; Coote 1992) were identified in the genome sequence of $V$. vulnificus.

Like $V$. cholerae, $V$. vulnificus infection can be acquired orally. Once entering the intestinal tract, however, the invasive bacteria take a direct route to cause septicemia in $V$. vulnificus infection. We examined virulence factors involved in this critical step of vibrio infections, that is, intestinal colonization and enterotoxic properties of the two pathogens. In cholera, TCP (toxin coregulated pilus), CTX (cholera toxin), and RTX are responsible for colonization, causing diarrhea and inducing inflammatory response in the intestine (Lin et al. 1999). The RTX locus of $V$. cholerae is on the large chromosome and it includes four genes $(r t x A, r t x C, r t x B$, and $r t x D)$ encoding the Rtx toxin, toxin activator, and associated transport system. In $V$. vulnificus, a homologous RTX gene cluster (VVA1030, VVA1032, VVA1034, VVA1035, VVA1036) is localized in a 22-kbp region on the small chromosome, but the region does not harbor a linked CTX cluster as in $V$. cholerae. The arrangement of RTX genes in this cluster is similar to that in $V$. cholerae, but the flanking sequences are different (Fig. 4D). On one side of the cluster, a sensor histidine kinase/response regulator in $V$. cholerae is replaced by a broadfunction dehydrogenase (VVA1037) in V. vulnificus. On the other side of the RTX gene cluster, CTX structural genes and bacteriophage elements, TLC and Rst genes, are present in the $V$. cholerae genome, whereas the $V$. vulnificus RTX genes are next to an alanine racemase gene (VVA1029). Interestingly, additional RTXlike molecules were found in the large chromosome (VV1546) and the small chromosome (VVA0331). Figure 4D displays the genomic organization of the RTX clusters and RTX paralogs identified in $V$. vulnificus.

\section{Comparative Analysis of $V$. vulnificus}

Previous studies reported that the genome of Vibrio species is organized into two replicons (Trucksis et al. 1998; Yamaichi et al. 1999), and recently, sequencing of $V$. cholerae El Tor N16961 confirmed that the $V$. cholerae genome indeed consists of a large 2.96-Mb chromosome and a small 1.07-Mb chromosome (Heidelberg et al. 2000). As more sequence information becomes available for Vibrio species (Heidelberg et al. 2000; Makino et al. 2003), it is now possible to conduct comparative analysis at the wholegenome level to address the issue of how Vibrio species evolved. Compared with $V$. cholerae, the genome of $V$. vulnificus is at least one megabase bigger, although both share the same organization as two circular replicons. Chromosome by chromosome, the large, first chromosomes are similar in size (3.4 Mb for $V$. vulnificus chromosome 1, VV1; $3.0 \mathrm{Mb}$ for $V$. cholerae chromosome
$1, \mathrm{VC} 1)$, whereas the small chromosome of $V$. vulnificus, designated VV2, is much larger than the corresponding small chromosome of $V$. cholerae, designated VC2 $(1.9 \mathrm{Mb}$ and $1.0 \mathrm{Mb}$ for VV2 and VC2, respectively). On the other hand, the two chromosomes of $V$. parahaemolyticus strain RIMD 2210633 are similar in size (3.3 Mb for VP1, 1.9 Mb for VP2) to those of $V$. vulnificus YJ016. We conducted chromosome-by-chromosome analysis of the $V$. vulnificus YJ016 sequence with the $V$. cholerae El Tor N16961 sequence and the $V$. parahaemolyticus RIMD 2210633 sequence to compare relative positions of conserved genes and to investigate the movement of genetic materials within and between the two chromosomes in the Vibrio species. As shown in Figure 5, V. vulnificus showed a higher degree of conservation in gene organization in the two chromosomes to $V$. parahaemolyticus than to $V$. cholerae. Moreover, the analysis revealed that the evolution of vibrio genomes is marked by multiple events of intra- and inter-chromosomal rearrangements, but the overall gene content and position in the large vibrio chromosomes are better conserved. The small chromosomes, on the other hand, are divergent in size and gene content between $V$. vulnificus and $V$. cholerae.

Gene duplication, leading to multiplication of paralogous groups, can be considered an incubator for genomic evolution, whereby functional diversity and gene dosage effects can be accomplished. In the $V$. vulnificus genome, members of a gene family are distributed either in a cluster or dispersed to two or more locations in the $V$. vulnificus genome. By comparing the number, distribution, and position of gene family members in the $V$. vulnificus and $V$. cholerae genomes, it appears that duplication and transposition events occurred more frequently in the $V$. vulnificus genome. Altogether, 260 duplication events added 495 genes to the $V$. vulnificus gene list, whereas only 113 events accounted for the addition of 147 genes to the $V$. cholerae gene list (data not shown). Thus, duplication could explain, in part, the expansion of genome size and the increase of gene number in $V$. vulnificus.

\section{DISCUSSION}

\section{The Evolution of Vibrio Genomes}

Genome sequence comparison among pathogenic Vibrio species revealed that certain genes are unique to $V$. vulnificus. Where are these sequences from? It is equally possible that species and strain specificity could be due to the acquisition of new genetic materials from an external source, or that genes could be present in a common vibrio precursor but subsequently deteriorated or eliminated from one species, thus becoming unique for the other. In the microbial world, genetic materials can be transmitted across a species barrier by several mechanisms. Conjugative plasmids, phages, phage-like elements, and transposable elements are the major vehicles for genetic exchange between genomes. Although it is difficult to retrace evolutionary events, a high degree of sequence identity to non-vibrio bacteria suggests that such sequence could have been acquired by horizontal transfer. For example, three operons (cyoA, $B, C$; proV, $W, X$; and fix $A, B, C)$ are uniquely present in the $V$. vulnificus small chromosome, and each is tandemly arranged as a single-copy cluster. Genes of the cyo, pro, and fix operons encode different components of cytochrome c oxidase (Schroter et al. 1998), the ABCtype proline/glycine betaine transport system (Gowrishankar 1989), and electron transfer flavoprotein, respectively (Weidenhaupt et al. 1996). Interestingly, sequences of these operons are related to homologous sequences in Pseudomonas aeruginosa, suggesting that these $V$. vulnificus-specific sequences might have originated from a distantly related bacterium. Although the mechanism through which these sequences were acquired remains unknown, the discovery of a plasmid that bears genes 
Chen et al.

0

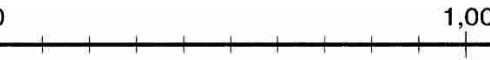

(1)

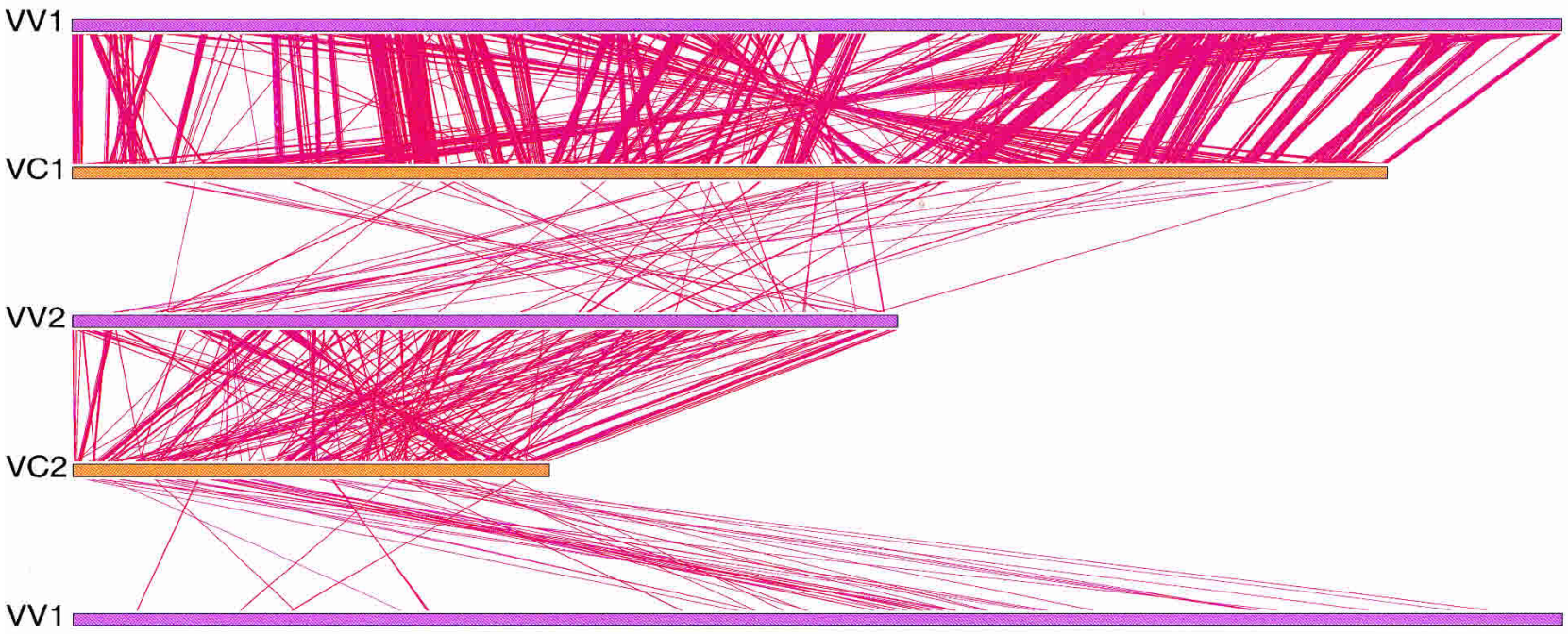

0

1,000

2,000

3,000

$\mathrm{Kbp}$

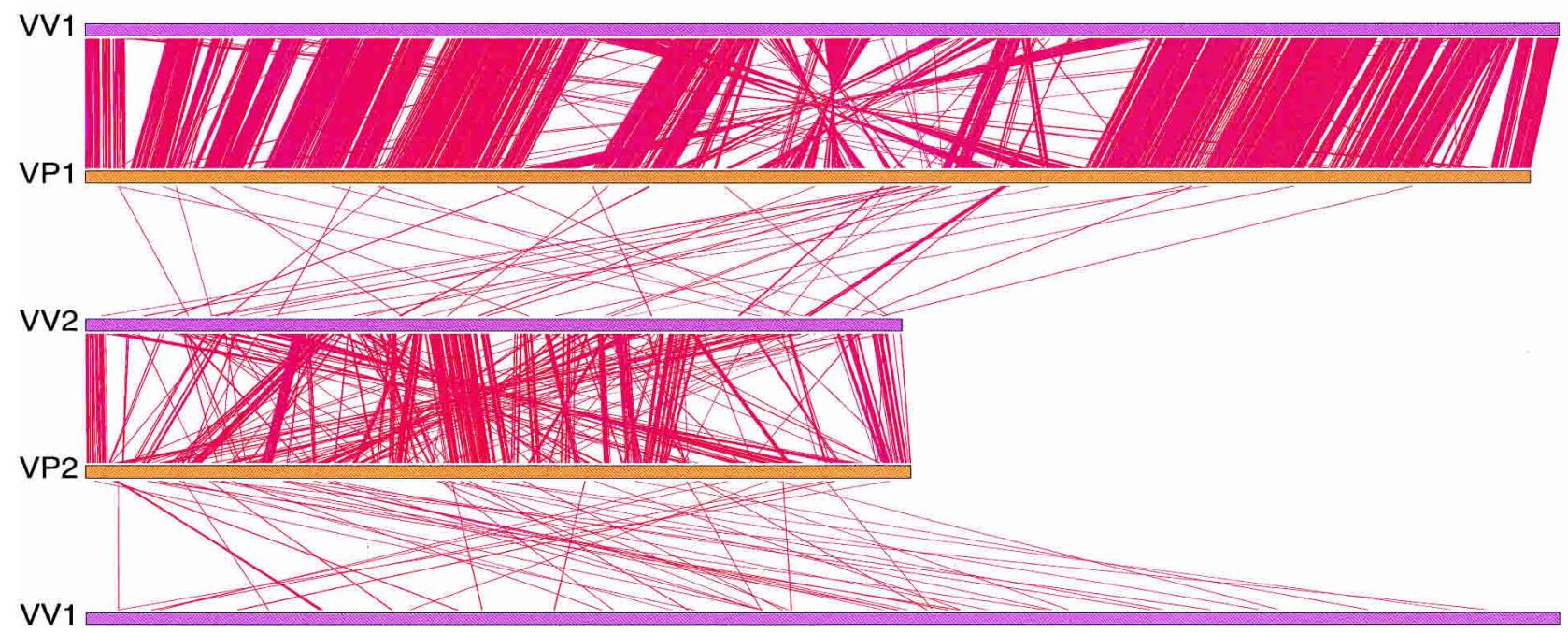

Figure 5 Intra- and interchromosomal shuffling of vibrio genes. VV1, V. vulnificus chromosome $1 ; \mathrm{VV} 2, V$. vulnificus chromosome 2; VC1, V. cholerae chromosome 1; VC2, V. cholerae chromosome 2. VP1, V. parahaemolyticus chromosome 1; VP2, V. parahaemolyticus chromosome 2 . See text for details. A homologous block of genomic sequence is indicated by a line between chromosomes; recombination events are represented by crossed lines.

capable of conjugation transfer and the identification of SI in the large chromosome are significant. Each provides a platform for capturing genetic materials and further disseminating foreign sequences in the chromosomes, thereby enriching the content of the genome.

As conjugation plasmid can mobilize chromosomal DNA by a recombination mechanism, it is possible that exchange of genomic information through this mechanism might be operational, to different degrees, among isolates of $V$. vulnificus. Preliminary analysis indicated that there is strain variation in the plasmid nature and sequence, and horizontal genetic exchange, enhanced by conjugation, might have contributed to the variability of genomic content of $V$. vulnificus (L.-I Hor, unpubl.).

The SI provides an additional source of genetic variability. Among the Vibrionaceae, SI has been identified in $V$. cholerae, $V$. mimicus, V. metschnikovii, V. parahaemolytiucs, V. anguillarum, and $V$. fischeri (Rowe-Magnus et al. 2001). The SI system represents a gene acquisition machinery that can incorporate ORFs and convert exogenous sequences into functional genes (Hall and Collis 1995; Rowe-Magnus et al. 1999), and this unique genetic system is widespread among the proteobacteria (RoweMagnus et al. 2001).

\section{Genome Research}

www.genome.org 
The content of the SI region is highly divergent between Vibrio species. Gene cassettes are unique among three Vibrio species of which the complete nucleotide sequence is currently available. Genome-wide, $V$ parahaemolyticus shares similar chromosomal organization with $V$. vulnificus (Fig. 5). It has a genome size $(5.2 \mathrm{Mb})$ close to that of $V$. vulnificus $(5.3 \mathrm{Mb})$, and the $V$. parahaemolyticus SI is also located on the large chromosome (Makino et al. 2003). However, the $V$. parahaemolyticus SI is entirely different from the $V$. vulnificus SI, suggesting that the SI of vibrio bacteria evolved rapidly. To confirm this notion we investigated, among $V$. vulnificus strains, the organization of SI sequences by Southern blot analysis. Four biotype 1 strains from Taiwan displayed distinct restriction fragment patterns for the PAS genes (Fig. 6A) and the mutT genes (data not shown). As a control, two housekeeping genes, aspartase (Fig. 6B), and G6PD (data not shown), revealed nearly identical patterns for the four isolates. Further, we analyzed the corresponding SI genes of the

A

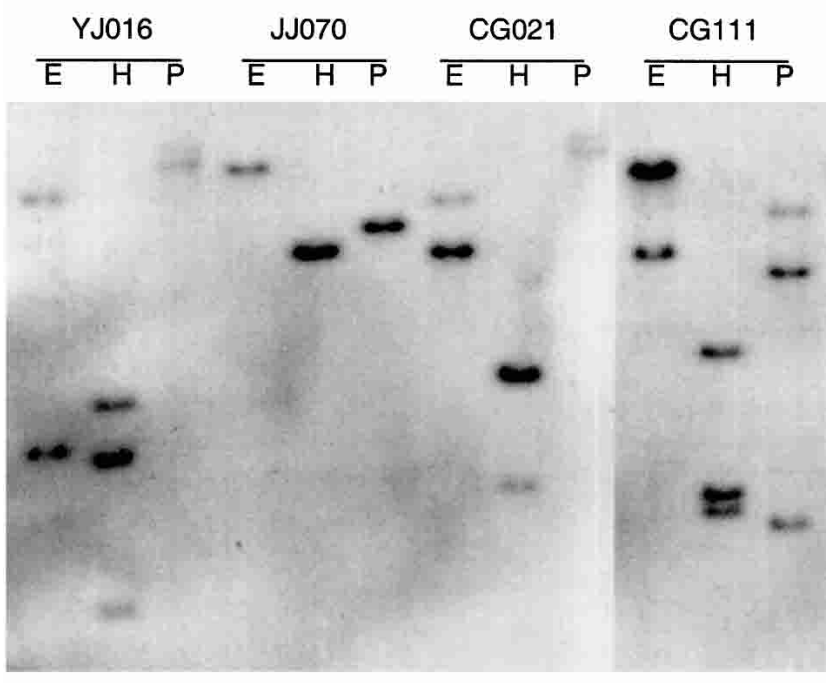

B

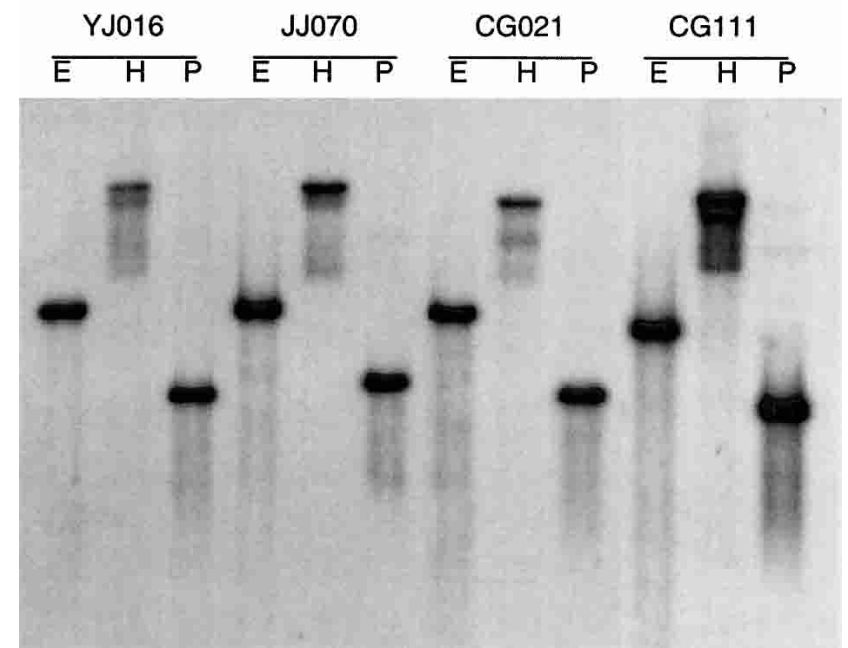

Figure 6 Southern blot analysis of $V$. vulnificus genes. Genomic DNA from four isolates was digested with $\operatorname{EcoRI}(\mathrm{E})$, HindIII $(\mathrm{H})$, and Pstl $(P)$. The filters were probed with $(A)$ PAS gene or $(B)$ aspartase gene. recently available genome sequence of a Korean isolate (AE016795, AE016796; Kim et al. 2003). In V. vulnificus CMCP6, the SI spans nearly $151 \mathrm{kbp}$ and the region harbors $211 \mathrm{attC}$ sites. The entrapped gene cassettes of the two strains are different, and 29 out of the 129 unique SI ORFs (103 singlets, 26 paralogous groups) from the YJ016 strain are conserved (with $\mathrm{E} \leq 10^{-15}$, amino acid identity $\geq 80 \%$ and over $80 \%$ of the query length) in the CMCP6 strain. However, only six ORFs (VV1774, VV1775, VV1791, VV1818, VV1831, VV1852) are completely identical between the two isolates. Thus, the low degree of conservation in gene content and coding sequence indicates that a significant divergence occurred in SI cassettes between $V$. vulnificus strains isolated from different geographic areas. Taken together, the genomic data collected so far from the vibrio bacteria suggest that the SI region is actively evolving and that it provides a driving force for genetic diversity and contributes to the development of species-specific and strain-specific features. It remains to be determined how the SI region acquires, filters, and propagates foreign sequences, and how these events take place at high frequency in a limited genomic location.

\section{Conclusion}

The genomic constitution and organization of $V$. vulnificus provide a vivid example of how gene duplication, recombination, and horizontal transfer could enrich the content of a bacterial genome during evolution. Rapid genomic evolution enabled Vibrio species to survive frequently changing conditions in an aquatic environment. The ability to acquire genetic materials from the rich ocean resource plus frequent duplication of genomic sequences provided $V$. vulnificus with a dynamic means of ecological adaptation. It appears that evolution and selection in the marine ecosystem diversify the biochemical properties of the bacteria, and humans that incidentally encounter a pathogenic strain fall victim to the virulence factors of the invading organism that has evolved independently of the host.

Finally, the unique biological features of Vibrio species present an accessible gateway for investigating the molecular events leading to genetic diversity of microbial organisms in the marine environment. The identification of multiple genes that potentially function in the bacterial invasion process of cell adhesion, colonization, cytotoxicity, and tissue destruction provides tangible material for further investigation. Given the genomic information, it is now possible to prepare appropriate bacterial knockout mutants and systematically analyze the role of each, individually or in combination. Further studies in animal models are required to identify virulence genes that make $V$. vulnificus an invasive human pathogen.

\section{METHODS}

\section{Bacterial Strain}

A virulent strain of $V$. vulnificus, YJ016, was used to construct shotgun libraries for genomic sequencing. This strain was obtained from National Cheng-Kung University Hospital, Taiwan and was isolated from the blood of a patient who suffered from primary septicemia. The isolate was confirmed to be of biotype 1 .

\section{Whole-Genome Shotgun Sequencing}

Published methods were applied for constructing whole-genome shotgun libraries (Fraser et al. 1997). Approximately sevenfold genome coverage was achieved using a small-insert library and another threefold genome coverage contributed by a large-insert library. A third cosmid library was used to collect over 2000 clone end sequences and to obtain a genome scaffold. Sequences were jointly assembled using Phred/Phrap/Consed software (obtained from the University of Washington, Seattle; Ewing and Green 1998; Ewing et al. 1998; Gordon et al. 1998). Accuracy, order, and 
orientation of contigs were examined on the basis of linking information from forward and reverse sequence ends of each clone. Sequence gaps were closed by editing the end sequences of each contig, primer walking on linking clones, and by sequencing PCR products from genome DNA or specific cosmid clones. Three restriction enzyme maps, NotI, SfrI, and I-CeuI, were constructed using pulse field gel electrophoresis (PFGE) and Southern analysis to cluster and locate the contigs. Restriction mapping confirmed the accuracy of the assembled YJ016 genomic sequences.

\section{Annotation}

CDS was identified by the GeneMark and Glimmer gene prediction programs (Borodovsky and McIninch 1993; Salzberg et al. 1998). A Hidden Markov model required by the GeneMark was generated by using the $V$. cholerae El Tor N16961 genome sequence as a training set. This HMM model has $98.6 \%$ accuracy to predict $V$. cholerae CDS of $150 \mathrm{bp}$ or longer. CDS identified by only one of the two programs and shorter than $150 \mathrm{bp}$ were dropped as noise. A Perl script automatically submitted ORF sequences into BLASTX against $\mathrm{nr}$ (nonredundant proteins), BCT (bacteria proteins), Refseq (NCBI reference sequences), VC (Vibrio cholerae proteins), and COGs. All results of BLASTX searches were automatically parsed into a MySQL database manager system for subsequent analysis. For each CDS, the ORF sequences and the sequences of BLASTX hits against six databases were retrieved, and they were automatically submitted into PS_scan and HMMER against PROSITE and Pfam, respectively. Pattern search results of motifs, domains, and function sites were used to validate the BLASTX similarity search results. After human inspection, the product name, gene name, COGID, functional category, enzyme number, and gene ontology of each CDS were then assigned automatically by the links to a MySQL relational database. tRNAs were predicted by tRNAscan-SE. rRNAs were identified by BLASTN against known $V$. vulnificus rRNA sequences. Repeat regions were identified by RepeatFinder (obtained from TIGR).

\section{Genome Comparison}

Chromosomal rearrangement and gene shuffling between $V$. vulnificus YJ016 and V. cholerae El Tor N16961, and between $V$. vulnificus YJ016 and $V$. parahaemolyticus RIMD 2210633 were analyzed by ORF homology search using BLASTP. Matches with over $80 \%$ of the query length and identity $\geq 60 \%$, and E-value $\leq 10^{-15}$ were drawn by Perl scripts and indicated as red lines. The nucleotide, protein sequences, and other annotation data of $V$. cholerae El Tor N16961 and V. parahaemolyticus RIMD 2210633 in this study were obtained from GenBank with accession numbers NC_002505, NC_002506, NC_004603, and NC_004605.

\section{Southern Analysis}

Four independent isolates of biotype $1 \mathrm{~V}$. vulnificus were subjected to Southern blot analysis. YJ016 and JJ070 were obtained from clinical specimens, and CG021 and CG111 were collected from the environment. Approximately $1 \mu \mathrm{g}$ of genomic DNA from each strain was digested with EcoRI, HindIII, PstI. PCRamplified fragments for SI genes, PAS (VV1767; nt position: 1,813,717-1,813,943; $227 \mathrm{bp}$ ) and mutT (VV1754; nt position: $1,803,504-1,803,903 ; 400 \mathrm{bp})$, and two housekeeping genes, aspartase (VV3118; 3,198,054-3,198,662; 609 bp) and G6PD (VV1605; 1,650,801-1,651,336; 536 bp) were used as the probes by random primer labeling (Rediprime II kit, Amersham Pharmacia). Hybridization and stringent washing conditions were based on the instructions for Hybond N+ (Amersham Pharmacia).

\section{ACKNOWLEDGMENTS}

We thank the staff of the Yang-Ming University Genomic Research Center (YMGC; http://genome.ym.edu.tw/) and the Genomics Department of the Biomedical Engineering Center (BMEC; http://www.bmec.itri.org.tw/) at the Industrial Research Technology Institute for their efforts and contributions. We thank Drs. T. Iida, K. Kurokawa, and M. Hattori for their sugges- tions on assembling the YJ016 genome from shotgun fragments, Dr. Michael Sievers for sharing his experience with CAP3 software (Paracel, CA) in assembling YJ016 shotgun sequences, Dr. Carton Chen for his assistance on PFGE and data analysis, and Jim Wang, Hsu-Tong Liu, and Henry Sun for critical reading of the manuscript. Funding to YMGC and this study were from the NHRI, NSC, and MOE of the R.O.C. A grant from the New Century Health Care Promotion Foundation provided the initial support for a pilot study on sequencing the YJ016 genome. L.-I.H. and C.H.C. are recipients of grants NSC90-2320-B-006-065 and NSC 91-3112-B-010-015 from the National Science Council of the R.O.C.

The publication costs of this article were defrayed in part by payment of page charges. This article must therefore be hereby marked "advertisement" in accordance with 18 USC section 1734 solely to indicate this fact.

\section{REFERENCES}

Blake, P.A., Merson, M.H., Weaver, R.E., Hollis, D.G., and Heublein, P.C. 1979. Disease caused by a marine Vibrio. Clinical characteristics and epidemiology. N. Engl. J. Med. 300: 1-5.

Borodovsky, M. and McIninch, J.D. 1993. Genemark: Parallel gene recognition for both DNA strands. Comput. Chem. 17: 123-133.

Chuang, Y.C., Yuan, C.Y., Liu, C.Y., Lan, C.K., and Huang, A.H. 1992. Vibrio vulnificus infection in Taiwan: Report of 28 cases and review of clinical manifestations and treatment. Clin. Infect. Dis. 15: $271-276$.

Collis, C.M., Kim, M.J., Stokes, H.W., and Hall, R.M. 1998. Binding of the purified integron DNA integrase Intl1 to integron- and cassette-associated recombination sites. Mol. Microbiol. 29: 477-490.

Coote, J.G. 1992. Structural and functional relationships among the RTX toxin determinants of gram-negative bacteria. FEMS Microbiol. Rev. 8: 137-161.

Dalsgaard, A., Frimodt-Moller, N., Bruun, B., Hoi, L., and Larsen, J.L. 1996. Clinical manifestations and molecular epidemiology of Vibrio vulnificus infections in Denmark. Eur. J. Clin. Microbiol. Infect. Dis. 15: $227-232$.

Ewing, B. and Green, P. 1998. Base-calling of automated sequencer traces using phred. II. Error probabilities. Genome Res. 8: 186-194.

Ewing, B., Hillier, L., Wendl, M.C., and Green, P. 1998. Base-calling of automated sequencer traces using phred. I. Accuracy assessment. Genome Res. 8: 175-185.

Fan, J.J., Shao, C.P., Ho, Y.C., Yu, C.K., and Hor, L.I. 2001. Isolation and characterization of a Vibrio vulnificus mutant deficient in both extracellular metalloprotease and cytolysin. Infect. Immun. 69: 5943-5948.

Fowler, R.G. and Schaaper, R.M. 1997. The role of the mutT gene of Escherichia coli in maintaining replication fidelity. FEMS Microbiol. Rev. 21: 43-54.

Fraser, C.M., Casjens, S., Huang, W.M., Sutton, G.G., Clayton, R. Lathigra, R., White, O., Ketchum, K.A., Dodson, R., Hickey, E.K., et al. 1997. Genomic sequence of a Lyme disease spirochaete, Borrelia burgdorferi. Nature 390: 580-586.

Gordon, D., Abajian, C., and Green, P. 1998. Consed: A graphical tool for sequence finishing. Genome Res. 8: 195-202.

Gowrishankar, J. 1989. Nucleotide sequence of the osmoregulatory proU operon of Escherichia coli. J. Bacteriol. 171: 1923-1931.

Hall, R.M. and Collis, C.M. 1995. Mobile gene cassettes and integrons: Capture and spread of genes by site-specific recombination. Mol. Microbiol. 15: 593-600.

Hayat, U., Reddy, G.P., Bush, C.A., Johnson, J.A., Wright, A.C., and Morris Jr., J.G. 1993. Capsular types of Vibrio vulnificus: An analysis of strains from clinical and environmental sources. J. Infect. Dis. 168: $758-762$.

Heidelberg, J.F., Eisen, J.A., Nelson, W.C., Clayton, R.A., Gwinn, M.L., Dodson, R.J., Haft, D.H., Hickey, E.K., Peterson, J.D., Umayam, L., et al. 2000. DNA sequence of both chromosomes of the cholera pathogen Vibrio cholerae. Nature 406: 477-483.

Hlady, W.G. and Klontz, K.C. 1996. The epidemiology of Vibrio infections in Florida, 1981-1993. J. Infect. Dis. 173: 1176-1183.

Kennedy, N., Beutin, L., Achtman, M., Skurray, R., Rahmsdorf, U., and Herrlich, P. 1977. Conjugation proteins encoded by the F sex factor. Nature 270: 580-585.

Kim, Y.R., Lee, S.E., Kim, C.M., Kim, S.Y., Shin, E.K., Shin, D.H., Chung, S.S., Choy, H.E., Progulske-Fox, A., Hillman, J.D., et al. 2003. Characterization and pathogenic significance of vibrio vulnificus antigens preferentially expressed in septicemic patients. Infect. Immun. Infect. Immun. 71: 5461-5471.

Lin, W., Fullner, K.J., Clayton, R., Sexton, J.A., Rogers, M.B., Calia, K.E., 
Calderwood, S.B., Fraser, C., and Mekalanos, J.J. 1999. Identification of a Vibrio cholerae RTX toxin gene cluster that is tightly linked to the cholera toxin prophage. Proc. Natl. Acad. Sci. 96: 1071-1076.

Linkous, D.A. and Oliver, J.D. 1999. Pathogenesis of Vibrio vulnificus. FEMS Microbiol. Lett. 174: 207-214.

Makino, K., Oshima, K., Kurokawa, K., Yokoyama, K., Uda, T. Tagomori, K., Iijima, Y., Najima, M., Nakano, M., Yamashita, A., et al. 2003. Genome sequence of Vibrio parahaemolyticus: A pathogenic mechanism distinct from that of $V$. cholerae. Lancet 361: 743-749.

Maneewannakul, K., Maneewannakul, S., and Ippen-Ihler, K. 1993. Synthesis of F pilin. J. Bacteriol. 175: 1384-1391.

Mazel, D., Dychinco, B., Webb, V.A., and Davies, J. 1998. A distinctive class of integron in the Vibrio cholerae genome. Science 280: 605-608.

Moore, D., Sowa, B.A., and Ippen-Ihler, K. 1981. The effect of tra mutations on the synthesis of the F-pilin membrane polypeptide. Mol. Gen. Genet. 184: 260-264.

Park, S.D., Shon, H.S., and Joh, N.J. 1991. Vibrio vulnificus septicemia in Korea: Clinical and epidemiologic findings in seventy patients. $J$. Am. Acad. Dermatol. 24: 397-403.

Rahn, A., Drummelsmith, J., and Whitfield, C. 1999. Conserved organization in the cps gene clusters for expression of Escherichia coli group $1 \mathrm{~K}$ antigens: Relationship to the colanic acid biosynthesis locus and the cps genes from Klebsiella pneumoniae. J. Bacteriol. 181: 2307-2313.

Rowe-Magnus, D.A. and Mazel, D. 1999. Resistance gene capture. Curr. Opin. Microbiol. 2: 483-488.

Rowe-Magnus, D.A., Guerout, A.M., and Mazel, D. 1999. Super-integrons. Res. Microbiol. 150: 641-651.

Rowe-Magnus, D.A., Guerout, A.M., Ploncard, P., Dychinco, B., Davies, J., and Mazel, D. 2001. The evolutionary history of chromosomal super-integrons provides an ancestry for multiresistant integrons. Proc. Natl. Acad. Sci. 98: 652-657.

Salzberg, S.L., Delcher, A.L., Kasif, S., and White, O. 1998. Microbial gene identification using interpolated Markov models. Nucleic Acids Res. 26: $544-548$.

Schroter, T., Winterstein, C., Ludwig, B., and Richter, O.M. 1998. Expression of the Escherichia coli cyo operon in Paracoccus denitrificans results in a fully active quinol oxidase of unexpected heme composition. FEBS Lett. 432: 109-112.

Shao, C.P. and Hor, L.I. 2000. Metalloprotease is not essential for Vibrio vulnificus virulence in mice. Infect. Immun. 68: 3569-3573.

Smith, A.B. and Siebeling, R.J. 2003. Identification of genetic loci required for capsular expression in Vibrio vulnificus. Infect. Immun. 71: $1091-1097$.

Stokes, H.W. and Hall, R.M. 1989. A novel family of potentially mobile DNA elements encoding site-specific gene-integration functions: Integrons. Mol. Microbiol. 3: 1669-1683.
Strom, M.S. and Paranjpye, R.N. 2000. Epidemiology and pathogenesis of Vibrio vulnificus. Microbes Infect. 2: 177-188.

Tatusov, R.L., Koonin, E.V., and Lipman, D.J. 1997. A genomic perspective on protein families. Science 278: 631-637.

Todd, E.C. 1989. Costs of acute bacterial foodborne disease in Canada and the United States. Int. I. Food Microbiol. 9: 313-326.

Tokugawa, K., Kakitani, M., Ishii, T., Nakamura, K., Masaki, H., and Uozumi, T. 1994. A novel protein secretion factor from a Vibrio species which operates in Escherichia coli. J. Biotechnol. 35: 69-76.

Trucksis, M., Michalski, J., Deng, Y.K., and Kaper, J.B. 1998. The Vibrio cholerae genome contains two unique circular chromosomes. Proc. Natl. Acad. Sci. 95: 14464-14469.

Weidenhaupt, M., Rossi, P., Beck, C., Fischer, H.M., and Hennecke, H. 1996. Bradyrhizobium japonicum possesses two discrete sets of electron transfer flavoprotein genes: fixA, fixB and etfS, etfL. Arch. Microbiol. 165: 169-178.

Wright, A.C., Simpson, L.M., and Oliver, J.D. 1981. Role of iron in the pathogenesis of Vibrio vulnificus infections. Infect. Immun. 34: $503-507$.

Wright, A.C., Simpson, L.M., Oliver, J.D., and Morris Jr., J.G. 1990. Phenotypic evaluation of acapsular transposon mutants of Vibrio vulnificus. Infect. Immun. 58: 1769-1773.

Wright, A.C., Powell, J.L., Kaper, J.B., and Morris Jr., J.G. 2001. Identification of a group 1-like capsular polysaccharide operon for Vibrio vulnificus. Infect. Immun. 69: 6893-6901.

Yamaichi, Y., Iida, T., Park, K.S., Yamamoto, K., and Honda, T. 1999. Physical and genetic map of the genome of Vibrio parahaemolyticus: Presence of two chromosomes in Vibrio species. Mol. Microbiol. 31: $1513-1521$

Zuppardo, A.B. and Siebeling, R.J. 1998. An epimerase gene essential for capsule synthesis in Vibrio vulnificus. Infect. Immun. 66: 2601-2606.

\section{WEB SITE REFERENCES}

http://genome.nhri.org.tw/vv/; Vibrio vulnificus YJ016 Web site with online supplemental information.

http://www.ncbi.nlm.nih.gov/COG/; The NCBI COG database; the database of Clusters of Orthologous Groups of proteins.

http://genome.ym.edu.tw/; National Yang Ming University Genome Research Center.

http://www.bmec.itri.org.tw/; Biomedical Engineering Center, Industrial Technology Research Institute.

Received February 24, 2003; accepted in revised form September 24, 2003. 


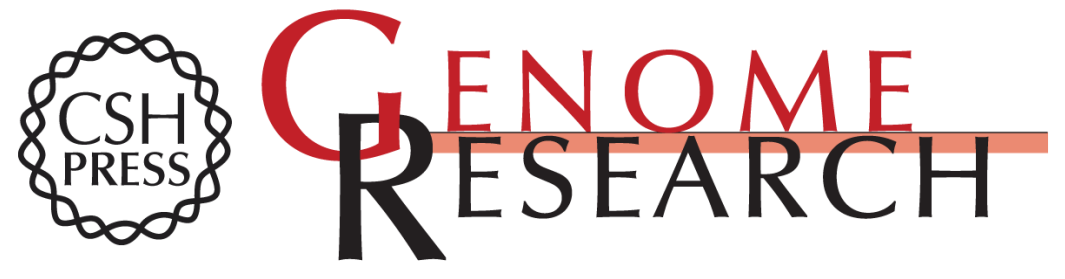

\section{Comparative Genome Analysis of Vibrio vulnificus, a Marine Pathogen}

Chung-Yung Chen, Keh-Ming Wu, Yo-Cheng Chang, et al.

Genome Res. 2003 13: 2577-2587

Access the most recent version at doi:10.1101/gr.1295503

Supplemental http://genome.cshlp.org/content/suppl/2003/12/02/13.12.2577.DC1

Material

References This article cites 45 articles, 18 of which can be accessed free at: http://genome.cshlp.org/content/13/12/2577.full.html\#ref-list-1

\section{License}

Email Alerting Receive free email alerts when new articles cite this article - sign up in the box at the Service top right corner of the article or click here.

\section{Affordable, Accurate Sequencing.}

To subscribe to Genome Research go to: https://genome.cshlp.org/subscriptions 